\title{
3D Analysis of gravel surface texture
}

Hong-Wei Yang ${ }^{1}$, Sergio DN Lourenco ${ }^{1 *}$, Béatrice A Baudet ${ }^{2}$, Clarence E Choi $^{3}$, Charles WW Ng${ }^{3}$

${ }^{1}$ Department of Civil Engineering, The University of Hong Kong, Pokfulam Road, Hong Kong

${ }^{2}$ Department of Civil, Environmental and Geomatic Engineering, University College London, London, Gower Street, LondonWC1E 6BT, UK.

${ }^{3}$ Department of Civil and Environmental Engineering, The Hong Kong University of Science and Technology, Kowloon, Hong Kong

${ }^{*}$ Corresponding author; Email: lourenco@hku.hk 


\section{ABSTRACT}

Surface texture plays an important role in understanding the mechanical and hydraulic behavior of a soil but has drawn little attention, especially for three dimensional parameters. Currently, the few studies on measurements and quantification of surface texture are limited to sand sized particles. To date, the surface texture of sand has been successfully obtained by using a high-resolution optical microscope for a given measurement area that is small and comparable to the sand particle size. However, for larger particles, such as gravel, the larger surface area may create difficulties. For instance, as the particle size increases, the surface texture could be influenced by other factors such as the mineral composition, scale-dependent fabric and others, hindering the simple extension of a method that quantifies the surface texture of sand to gravel. This paper attempts to address this challenge by proposing a method to measure and quantify the surface texture of gravel which explicitly takes into account the different texture scales. Crushed granite is taken as the testing material. To explore the surface texture at different scales, a 3D laser scanner (at millimeter scale) and a high resolution optical microscope equipped with interferometry (at micrometer scale) have been employed. The novel method defines and quantifies the surface texture of gravel with the aid of the power spectral density function (PSD) and a fractal method. It was found that the fractal dimension at the two different scales do not coincide, which might be interpreted as two different self-affine patterns of the surface. For example, the features of single minerals (e.g. fractures, cleavage, hardness) dominate at the small scale and become less prominent at the large scale where grain size and shape prevail. When a single fractal dimension from PSD at the large scale is assumed for both scales, the associated error can be quantified using the square root of the surface height to a mean plane and is found to be within $15 \%$. This 
suggests that the surface texture examined at a large scale by using the 3D laser scanner could be representative of the gravel, though cautions should be taken in individual cases for any quantitative studies of the effect of the surface texture.

Keywords: Surface texture; fractal dimension; power spectrum; gravel 


\section{INTRODUCTION}

Surface texture, also known as surface morphology or surface finish, refers to the finest morphological features on the surface and has been identified as a key factor in understanding the interfacial contact behaviors between two objects and has led to a substantial body of research in the fields of tribology and industrial manufacturing. Its role has also been recognized increasingly in granular materials, such as soils, in particular, in the interfacial frictional behavior, the contact stiffness, the wave propagation and the stiffness increase of granular assemblies (e.g. [1-5]).

The surface texture of naturally occurring soil particles has been qualitatively related to many factors including geological origin (e.g. igneous, erosion or sedimentary rock etc), the type of weathering (mechanical or chemical) and transportation history (e.g. by aeolian, glacial or alluvial means). For example, the surface texture of soil particles subjected to river erosion tend to be smooth (e.g. [6]) whereas soil particles subjected to glacial movement have striations [7] which roughen the surface. Different minerals, under breakage, also form different microfeatures such as fractured surfaces, micro-cracks and others. For instance, a conchoidal fracture frequently occurs for quartz particles whereas cleavage controls fracture for feldspar and mica. In general, the freshly created surfaces are smoother than naturally weathered surfaces [8], as surfaces of minerals such as feldspar could develop micro-pores and etched pits or depressions due to dissolution (e.g. [9-10]). Quartz particles, for instance, could develop specific topographic features (e.g. vshaped depressions and straight or slightly curved scratches) depending on the environment they evolved [11]. Particle size also plays a role on surface texture. As the particle size increases, micro-fractures due to imperfections and brittle fracturing [12] dominate over surfaces related to cleavage [13]. 
For the quantitative description of the surface texture, a representative value of the surface texture has usually been adopted, such as the square root of the surface heights to a mean plane $S_{\mathrm{q}}$ (e.g. [2, 14-15]) or fractal dimension (e.g. [16-17]). The $S_{\mathrm{q}}$ has been frequently used mainly due to its simplicity. But it has long been recognized that $S_{\mathrm{q}}$ is resolution-dependent (e.g. [18]). This has prompted the use of a scaleindependent fractal dimension which arises from a hierarchical structure of the surface (e.g. [19]). For example, at lower resolutions, a surface may have peaks and valleys with relatively large spacing (such as dents and hills) on which when superimposed at higher resolution, a series of peaks and valleys of similar form and smaller spacing could be observed.

Three-Dimensional (3D) surface measurements have been preferred over 2D where a single projection of a particle outline was normally used resulting in random and inaccurate values with details of the surface being lost. So far, a 3D analysis of surfaces has been made possible with the development of suitable testing apparatus, such as optical interferometry (e.g. [2,4,20-23]) and X-ray micro ComputedTomography (CT) [24]. However, all of these are limited to sand-sized particles. In general, the optical interferometry can measure a surface at a small scale which is accompanied by a limited measurement area. Multiple measurements at different locations on a single particle would thus be needed to achieve an asymptotic representative value of the surface [23]. But a larger particle leads to larger surface area and requires more surface measurements, which is time-intensive. This could be further complicated by the presence of different minerals on the particle surface which is not uncommon for coarser particles. On the other hand, a whole surface could be obtained by using an instrument such as the micro CT. But the particle surface examined is at a relatively large scale due to its low resolution which decreases with 
the particle size. Therefore, a method to measure and quantify the surface texture of coarse particles which takes into account the different topographic scales is needed.

This paper examines the surface texture of gravel of crushed granite at two different scales, (1) at large scales (with the resolution at mm magnitude) where the surface texture is examined with a 3D laser scanner and, (2) at small scales (with the resolution at $\mu \mathrm{m}$ magnitude) by optical interferometry. The 3D laser scanner is preferred as it is easier to handle and requires less time in comparison to other methods, such as the micro-CT (e.g. [25]). To enable the surface measurements to be compared at the two scales a new method is proposed whereby an open surface from digitized particles is defined and analyzed by fractal analysis using the power spectral density method [22].

\section{TEST MATERIALS AND INSTRUMENTS}

\subsection{Gravel and sand}

Testing particles are made of crushed granitic rockwhich is of elongated and angular shape. Gravel ranging from $5 \mathrm{~mm}$ up to $25 \mathrm{~mm}$ were grouped into two sizes, $5 \sim 10$ $\mathrm{mm}$ and 10 25 mm for easy handling. Around 30 particles were collected randomly from each size group. More than 20 particles have been suggested to investigate the morphological features (e.g. [26]). Since crushed granite is composed of mafic (e.g. biotite) and felsic minerals (e.g. plagioclase feldspar and quartz), additional particles at a sand size of 1.18 to $2 \mathrm{~mm}$ were selected to supplement the surface texture data at small scale. Twenty fiveparticles for each mineral type were randomly selected. 


\subsection{Instruments}

Two instruments are used to measure the surface texture of gravel-sized and sandsized particles. For convenience, surface texture measured by the 3D laser scanner and optical interferometry is referred to as large scale and small scale, respectively. Also, gravel-sized and sand-sized particles are referred to as gravel and sand, respectively.

\subsubsection{D laser scanner for the surface texture at large scales}

3D laser scanners have been used for scanning large particles, such as ballast in pavements (e.g. [27-29]). Here, a 3D laser scanner is employed (LPX-60, Roland DG Corporation, Hamamatsu, Japan). The chamber of the scanner can accommodate samples with dimensions up to $203 \mathrm{~mm}$ in diameter and $304.8 \mathrm{~mm}$ in height. The precision is up to $0.2 \mathrm{~mm} / \mathrm{scanning}$ pitch (distance between scanned points) in vertical direction and $0.2 \mathrm{~mm} /$ degree in circumferential direction.

During scanning, particles were fixed with a double sticky tape adhered to a holder. The contact area between the particle and the holder was controlled to be as small as possible, so that the un-scanned area could be minimized. The integrated software (Dr. PICZA3) enables the removal of the holder and triangular meshing of the scanned data points. The finest size of mesh in the software was used in order to preserve the morphological details.

\subsubsection{Optical interferometry for the surface texture at small scales}

Optical interferometers have been used for scanning small sand-sized particles (e.g. $[20,22])$. Here, we used the white light interferometry of an optical microscope (M3D 3000, Fogal Nanotech, France). The surface topography is described by an 
interferogram that is a function of the sample height at discrete points. The measuring area is up to $141.3 \times 106.6 \mu \mathrm{m}$ with the best in-plane (perpendicular to surface height) resolution being $0.184 \mu \mathrm{m}$ and $3 \mathrm{~nm}$ resolution in the surface height direction [22].

From the optical interferometry, an open surface with a measuring area of $106.6 \times 106.6 \mu \mathrm{m}$ was acquired, corresponding to $578 \times 578$ discrete points. Depending on the size of the particle, measurements of a single particle were repeated differently. For gravel, around five measurements were made on each particle. In total, 14 particles were tested leading to 67 measurements. For sand, three measurements per particle might provide representative values, according to [23]. In total, 75 particles were tested.

Table 1 summarizes the application of individual instrument to measurement of surface at a particular leng scale.

Table 1. Application of instruments to the material and the scale

\begin{tabular}{llll}
\hline \multirow{2}{*}{ Instruments } & \multicolumn{2}{l}{ Materials } & Scales of the surface measurements \\
\cline { 2 - 3 } & Gravel & sand & \\
\hline 3D laser scanner & $\sqrt{ }$ & & Large scale \\
Optical interferometer & $\sqrt{ }$ & $\sqrt{ }$ & Small scale \\
\hline
\end{tabular}

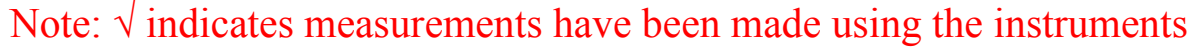

\section{NOVEL METHOD TO DEFINE AND QUANTIFY SURFACE TEXTURE}

\section{OF GRAVEL}

\subsection{Method to define surface texture from a digitized particle}

To determine the surface texture of digitized particles from the 3D laser scanner, a new method is proposed. This involves two main steps, (1) defining the open surface from digitized particle and (2) the separation of the surface texture from particle shape (Figure 1). 


\section{a. Principal component analysis on surface points}

The digitized particle is represented by the surface point or vertex of the triangular meshes. To obtain the principal axes of a scanned particle the principal component analysis (PCA) has been successfully applied by simplifying the complexity in highdimensional data (e.g. [30]). Taking advantage of the method to reduce the dimensionality of data, we could express the surface in the form $(h=f(x, y))$ when the particle is split horizontally into two parts.

\section{b. Determination of the spatial interval of surface points in digitized particles}

The spatial interval or distance of two adjacent surface points on a digitized particle varies mainly due to the irregular shape of the particles and could not be directly obtained from the resolution of the testing apparatus. The spatial distance is important in the following steps and has to be determined. Therefore, we evaluated the spatial distance by using a cube of a particular length to down sample the surface points. In this way, the surface points enclosed by the cube are merged into one point while the overall shape is preserved. The reduction in the number of total points then serves as an indicator of the spatial interval. At a sampling cubic length of around $0.05 \mathrm{~mm}$, the number of points is more than $90 \%$ of the original. A triangular meshing was performed again using this length to resample the data points using the open source software Meslab [31] in which the ball-pivoting algorithm [32] was adopted.

\section{c. Separating the digitized particle into two halves}

Firstly, the detection of the particle edge on the projection of the particle on the $(x, y)$ plane is performed, which enables fitting a surface to these edge points. The surface points with a height larger than the fitted surface constitutes the upper halve while the 
remaining surface points constitute the lower halve (Figure 2). Secondly, the points on each halved surface are then square gridded in the form of $h=f(x, y)$. The grid size is determined by the pre-determined spatial interval.

\section{d. Obtaining a square area on each separated surfaces}

To obtain a square open surface from each of the halved surfaces (Figure 3), the following criteria were used: (1) the largest possible square area on each halved surface was used in order to include more surface features and, (2) the obtained area was free of concave areas which might result in the re-entrant points [33].

\section{e. Separation between surface texture and particle shape using Power Spectral density}

The surface textures for gravel were then separated by using the Power Spectrum Density (PSD) method as adopted by Yang et al. [22] in which a single threshold value separating two morphological scales was used. The PSD is given by [18]:

$$
\operatorname{PSD}\left(q_{x}, q_{y}\right)=\frac{1}{(2 \pi)^{2}} \iint_{-\infty}^{\infty} A(x, y) e^{-i\left(x q_{x}+y q_{y}\right)} \mathrm{d} x \mathrm{~d} y
$$

where $A(x, y)$ is the auto-correlation function of surface heights $h(x, y)$ and $q$ is the spatial frequency or wavevector $\left(\right.$ in $\mathrm{mm}^{-1}$ ). A routine angular averaging can then be performed where the surface is assumed to be isotropic so that the $\operatorname{PSD}\left(q_{\mathrm{x}}, q_{\mathrm{y}}\right)$ reduces to $\operatorname{PSD}(q)$ and is independent of the $x$ or $y$ direction [34]. The calculation of PSD involves approximating the surface by a continuous function in which Fourier transform in involved. The surface could thus be regarded as a superposition of waves of various frequencies. Broadly speaking, the PSD thus reflects the proportion of each 
wave component. Detailed explanations of the physical meaning of PSD could refer to e.g. $[18,40]$.

Here, the threshold value was chosen to be the radius of the largest inscribed sphere inside a particle, $R_{\text {ins }}$ by considering the following: First, surface texture corresponds to the finest morphological features relative to the size of the particle whose overall shape varies. This can be reflected by the value of $R_{\text {ins }}$ which changes with the size and shape of a particle. Second, some regions where the curvature is larger than $1 / R_{\text {ins }}$ should be considered as a feature of the surface, as suggested by Nie et al. [35] who followed the roundness definition of Wadell [36]. Therefore, the surface texture of the gravel could be represented by the PSD with $q \geq 2 \pi / R_{\text {ins. }}$.

The value of $R_{\text {ins }}$ was determined using the distance map which registers the shortest distance between a point inside the particle and the surface points of the particle [37-38]. The largest value in the distance map is then $R_{\text {ins. }}$ To determine the points inside the particle, a total of 27000 gridded data points were created. The number is slightly more than half of the largest number of data points for the largest particle tested (larger than $25 \mathrm{~mm}$ ).

\subsection{Quantification of the surface texture using a fractal approach}

The surface textures for both gravel and sand were then analyzed using the fractal approach by the PSD method as adopted by Yang et al. [22]. The method is based on a stochastic formation process and suited to natural surfaces which usually exhibit self-affine features (with scales different in the vertical and in-plane directions) [39]. The proposed method to define surface texture from a digitized particle enables the surface texture to be compared at two different scales. 
The PSD follows a power law when $q \geq q_{\mathrm{c}}$, where $q_{\mathrm{c}}$ is a threshold wavevector indicating the length scale separating two morphological scales and is related to the $R_{\text {ins. }}$ This is expressed as [18]:

$$
\operatorname{PSD}\left(q \geq q_{c}\right)=C_{0}\left(q / q_{c}\right)^{2 D_{\mathrm{PSD}}-8}
$$

where $D_{\mathrm{PSD}}$ is the fractal dimension relating to the slope of the straight fitting line in the double logarithmic plane of PSD versus $q$ and $C_{0}$ is related to the intercept and $q_{\mathrm{c}}$ where a larger $q_{\mathrm{c}}$ leads to a smaller $C_{0} . S_{\mathrm{q}}$ can also be obtained from the PSD as follows:

$$
S_{\mathrm{q}}=\left(2 \pi \int_{q_{c}}^{q_{1}} P S D(q) q \mathrm{~d} q\right)^{0.5}
$$

$S_{q}$ could be calculated assuming a fractal relationship $[19,22]$. Combining Eqs (2) and (3) leads to:

$$
S_{\mathrm{q}}=\left(2 \pi \frac{q_{c}{ }^{2} C_{0}}{2 D_{P S D}-6}\left(\left(q_{1} / q_{c}\right)^{2 D_{P S D}-6}-1\right)\right)^{0.5}
$$

where $q_{1}$ is the largest wavevector and relates to the spatial interval (for 3D laser scanner) or resolution of the interferometer.

Power and Tullis [40] suggested $D_{\mathrm{PSD}}$ and $C_{0}$ to be the two basic fractal parameters from the PSD method. To demonstrate the physical significance of the fractal parameters $D_{\mathrm{PSD}}$ and $C_{0}$, we used the method of Persson et al. [18] (which 
represents the inverse of Eq. (1)) to reconstruct fractal surfaces by keeping other parameters, grid size or resolution and size of reconstructed area, constant. Different fractal surfaces have been generated according to different input PSDs as shown in Figure 4. Figure 4 (a) shows the effect of fractal dimension on the input PSD and thus the regenerated surfaces. By varying the value of fractal dimension, the slope $(<0$ and equals to $2 D_{\mathrm{PSD}^{-}} 8$ ) of the PSD has been varied. It can be seen that a larger fractal dimension leads to denser profiles (larger extent of the area occupied by the surface asperities). The resulting roughness of the surface can be indicated by the $S_{q}$ value which increases as the DPSD increases. This indicates that a higher DPSD results in a rougher surface. Figure 4 (b) shows the effect of $\mathrm{C}_{0}$ on the input PSD and subsequently on the generated surfaces. Different values determine the intercept of the PSD. The value of $\mathrm{C}_{0}$ reflects the magnitude of the spatial frequencies. Note that the magnitude of the vertical axis increases with larger $\mathrm{C}_{0}$ values, though the appearances of the regenerated surfaces with different $\mathrm{C}_{0}$ values seem very similar. The surface with a larger $\mathrm{C}_{0}$ value is accompanied with a larger $\mathrm{S}_{\mathrm{q}}$ value, which indicates a resulting rougher surface.

To show how the fractal parameters, $D_{\mathrm{PSD}}$ and $C_{0}$ are obtained, an example is given in Figure 5 by applying the fractal approach on two projected square areas of $18.6 \times 18.6 \mathrm{~mm}^{2}$ from a gravel-sized particle (Figure 9 (a)). The fractal parameters are shown in Figure 9 (b) and are obtained by fitting a straight single line through the PSD data bounded by the $q_{1}$ (related to the spatial interval) and $q_{\mathrm{c}}$ values. A similar example is shown in Figure 6 for a sand particle where a straight line is fitted from the point below which the PSD is constant up to the $q_{1}$ value. Note that for sands, the surface as measured by interferometry is at the length scale much smaller than that of 
gravel as measured by the 3D laser scanner, therefore the measurements by interferometry was regarded directly as the surface texture for sand and the procedure defining the surface texture was not conducted. The proposed method to define and quantify the surface texture of gravel was then applied to gravel particles of two size groups, 5 10 $\mathrm{mm}$ and 10 25 $\mathrm{mm}$.

\section{RESULTS AND DISCUSSION}

\subsection{General features of the surface texture}

Error! Reference source not found.Figure 7 shows representative results for sand particles $(1.18 \sim 2 \mathrm{~mm})$. The cleavage planes with flat planar surfaces can be observed for biotite (Error! Reference source not found.Figure 7a, b, c) and feldspar (Error! Reference source not found. Figure 7d, e, f). The surfaces become slightly rougher with the presence of small micron sized pits or depressions (Error! Reference source not found. Figure 7e and c) and jagged edges (Error! Reference source not found.Figure 7 b). For quartz, concoidal fractures (Error! Reference source not found. Figure $7 \mathrm{~g}$ and $\mathrm{h}$ ) and arched-like steps (Error! Reference source not found.Figure 7i) can be observed. Similar features have been reported elsewhere (e.g. [41-42]). At a large scale, the surface is undulating with an interlocking texture and tight grain boundaries. Other features, e.g. different grain sizes and shapes, degree of orientation, relative proportions of grains, mechanical and weathering mechanism [43] become apparent to the outlook of the surface texture.

\subsection{Quantification of surface texture at small and large scales}

Figure 8 and Figure 9 show the fractal dimensions and the fractal parameter $C_{0}$ at both large (from 3D laser scanner) and small (from interferometry) scales, respectively. 
Surface measurements on gravel were numbered from 1 to 67 whereas on sand it was numbered from 68-92.

For the fractal dimension of gravel (with size ranges of 5 10 mm and 10 25 $\mathrm{mm}), D_{\mathrm{PSD}}$, at a large scale, the average value is around 2.57 and there is no remarkable difference for the two size groups of gravel though the data variation in the smaller size is slightly larger. At a small scale, referring to Table 1 the interferometry has been used to examine the small-scale surface texture and both gravel and sand of three mineral types were measured. It can be seen that from Figure 8 that the values of $D_{\mathrm{PSD}}$ for sand of all three mineral types are indiscernible being around 2.42 which are within the same range as gravel (from 2.35 to 2.5).

A comparison of the fractal dimensions at large and small scales reveals noticeable differences with the $D_{\mathrm{PSD}}$ value being smaller at the small scale than that at the large scale. Referring to Figure 4a in which the physical meaning of the $D_{\mathrm{PSD}}$ has been shown, a larger value indicates a denser profiles. The different values at each scale indicate different self-affine pattern prevails, which is in agreement with the topographic features. At a small scale, the topographic features of single minerals (e.g. fractures, cleavage, hardness etc) dominate and become less prominent at larger scales where the observed features depend on the relative proportion of grains with different mineralogy, their arrangement, sizes and shapes.

For $C_{0}$, at a large scale, the values are at the magnitude ranging from $10^{-5}$ to $10^{-1}$ with larger particles $(10 \sim 25 \mathrm{~mm})$ having slightly larger values than particles in the range $5 \sim 10 \mathrm{~mm}$. This is due to the slightly smaller $q_{\mathrm{c}}\left(=2 \pi / R_{\text {ins }}\right.$ in which $R_{\text {ins }}$ is generally larger for a larger particle and ranges from $1.1 \mathrm{~mm}$ to $6.5 \mathrm{~mm}$ ). In comparison, at a small scale, the values are of several orders of magnitude smaller. Yang [18] found that there is unique relation between $C_{0}$ and $S_{\mathrm{q}}$ (from Eq (2)) through 
$S_{\mathrm{q}}=\mathrm{a}^{*} C_{0}$. where $a$ and $b$ are fitting parameters. Note that different sets of fitting parameters are found for sand (1.9 and 0.32) and gravel (291.6 and 0.49) (Figure 10). These two distinct relationships could also be due to the two different surface features of sand and gravel.

\subsection{Defining a fractal dimension for gravel}

Different sets of fractal parameters have been found at the large and small scales. Here, we explore the possibility of using the set of fractal parameters for the large scale to represent the surface texture of gravel. Figure 11 shows the PSD at both large and small scales. At a large scale, the threshold wavevector range is indicated by vertical black lines which are related to the radius of the largest inscribed sphere inside the particle by $2 \pi / R_{\text {ins }}$, in which $R_{\text {ins }}$ ranges from $1.1 \mathrm{~mm}$ to $6.5 \mathrm{~mm}$ for the gravel. A larger $q_{\mathrm{c}}$ is thus a direct result of a smaller $R_{\text {ins }}$ for smaller gravel-sized particles. Also, in an attempt to use the same $D_{\text {PSD }}$ to represent the surface at both scales, a bold black line, which is the average PSD at a large scale, is extended to the small scale range. The error associated with this attempt can be quantified with $S_{\mathrm{q}}$, as the $S_{\mathrm{q}}$ value could alternatively be obtained from the PSD of the surface by using Eq. (4) in which the PSD was expressed in terms of fractal parameters. (Figure 12). Two $S_{\mathrm{q}}$ values have been obtained and compared, (1) $S_{\mathrm{q}_{-} \mathrm{W}}$ when the same $D_{\mathrm{PSD}}$ from a large scale is extended to a small scale and, (2) $S_{\mathrm{q} \_} \mathrm{r}$ when a different $D$ PSD is adopted for different scales. In determining $S_{\mathrm{q} \_} \mathrm{r}$, average values of $C_{0}$ and $D_{\mathrm{PSD}}$ are used at small scale. The differences between these two values are at the magnitude of $1 \mu \mathrm{m}$ with the error increasing as the particle size decreases accompanied with a decrease in $S_{\mathrm{q}}$. Nonetheless, most of the data are bounded by a $15 \%$ error line. This suggests that 
assuming a single value of $D_{\text {PSD }}$ for both scales might not cause a significant error when using $S_{\mathrm{q}}$.

\subsection{Implications for surface texture measurements in granular materials}

The results revealed that the fractal parameters at large and small scales do not coincide. This suggests that a single set of $D_{\mathrm{PSD}}$ and $C_{0}$ is not sufficient to represent the surface texture at both large and small scales. However, the values at a large scale might be used to represent the gravel particles if the $S_{\mathrm{q}}$ error is within $15 \%$. The value of $S_{\mathrm{q}}$ at the large scale is much larger than that at the small scale as the spatial frequencies at large scales lead to larger values (Figure 10 and Figure 11). One of the advantages of using a single fractal dimension is that the surface texture can be obtained from the $3 \mathrm{D}$ laser scanner which is relatively more accessible compared to other advanced and expensive apparatus such as the micro CT and optical interferometry. This might facilitate future research on the surface texture of gravel and other granular materials. For example, Sarocchi et al. [44] showed that in dense debris flows where large particles are often encountered particles at different heights are subjected to different mechanisms, such as rolling and sliding, collision and friction. The different mechanism results in different appearances of the surface which has been used to indicate the mechanism the particle were subjected to.

\section{CONCLUSION}

This paper investigates the surface texture of gravel at large scales (mm magnitude) using a 3D laser scanner and at small scales ( $\mu \mathrm{m}$ magnitude) using optical interferometry. A novel method is proposed to extract and quantify the surface texture from digitized particles acquired from a 3D laser scanner. The surface texture at two 
different scales were compared by means of fractal parameters from the power spectral density function (PSD) and $C_{0}$ (which relates to the intercept of the straight fitting line between PSD and wavevector in the double logarithmic plane). It was found that both the fractal dimension and $C_{0}$ were different at the two scales. Specifically, the surface texture at a large scale showed larger values in these two parameters. This could be attributed to different topographic features dominating at each scale. For example, at a small scale the features revealed by single minerals (e.g. fractures, cleavage, hardness) dominate whereas at large scales the surface texture might be interpreted as a random combination of grains with different sizes and shapes and mineralogy's. The assumption of using a single fractal dimension to represent the surface texture of large particles has also been examined with the PSD method. The resulting error was quantified with the $S_{\mathrm{q}}$ value. Assuming a single value of $D_{\mathrm{PSD}}$ obtained from the surface measurement at a large scale (based on the 3D laser scanner) for both scales might not cause significant error in the $S_{\mathrm{q}}$. This finding might make it possible to examine the surface texture of gravel and other similar sized granular materials by means of a 3D laser scanner alone which is relatively more accessible compared to other advanced and expensive apparatus such as the micro CT and optical interferometry. 


\section{ACKNOWLEDGEMENTS}

The authors acknowledge the financial support provided by the Research Grants Council of HKSAR (17200114, TR22-603-15N).

\section{REFERENCES}


[1] C. Santamarina, G. Cascante, Effect of surface roughness on wave propagation parameters, Géotechnique 48 (1998) 129-136.

[2] M. Otsubo, C. O'Sullivan, W.W. Sim, E. Ibraim, Quantitative assessment of the influence of surface roughness on soil stiffness, Géotechnique 65 (2015) 694-700.

[3] C.S. Sandeep, K. Senetakis, Effect of Young's Modulus and Surface Roughness on the Inter-Particle Friction of Granular Materials, Materials, 11 (2018) E217

[4] M. Otsubo, C. O'Sullivan, Experimental and DEM assessment of the stress dependency of surface roughness effects on shear modulus, Soils. Found. Available online.

[5] R.L. Michalowski, Z. Wang, S. S. Nadukuru, Maturing of contacts and ageing of silica sand, Géotechnique 68 (2018) 133-145

[6] M. Attal, J. Lave, Pebble abrasion during fluvial transport: experimental results and implications for the evolution of the sediment load along rivers, J. Geophys. Res. 114 (2019) F04023

[7] J.E. Bullard, 14.20 Examining Particle Shape. (2013) 243-256.

[8] C. Anbeek, Surface roughness of minerals and implication for dissolution studies, Geochim. Cosmochim. Acta. 56 (1992) 1461-1469

[9] R.A. Berner, G.R. Holdren Jr, Mechanism of feldspar weathering-II. Observations of feldspars from soils, Geochim. Cosmochim. Acta. 43 (1979) 1173-1186.

[10] M.R. Lee, L. Parsons, Microtextural controls of weathering of perthitic alkali feldspars, Geochim. Cosmochim. Acta. 59 (1995) 4465-4488.

[11] D.H. Krinsley, J.C. Doornkamp, Atlas of quartz sand surface textures, Cambridge University Press, Cambridge, 1973.

[12] S.V. Margolis, D.H. Krinsley, Processes of formation and environmental occurrence of microfeatures on dentrital quartz grains, Am. J. Sci. 274 (1974) 449-465.

[13] D.H. Krinsley, I.J. Smalley, Shape and nature of small sedimentary quartz particles, Science, 180 (1973) 1277-1279. 
[14] S. Yimsiri, K. Soga, Micromechanics-based stress strain behaviour of soils at small strains, Géotechnique 50 (2000) 559-571.

[15] F. Scharinger, H.F. Schweiger, G.N. Pande, On a multilaminate model for soil incorporating small strain stiffness, Int. J. Numer. Anal. Methods Geomech. 33 (2008) $215-243$.

[16] A.H. Hanaor, Y. Gan, I. Einav, Effects of surface structure deformation on static friction at fractal interfaces, Géotech. Lett. 3 (2013) 52-58.

[17] A.H. Hanaor, Y. Gan, M. Revay, D.W. Airey, I. Einav I. 3D printable geomaterials, Géotechnique 66 (2016) 323-332.

[18] B.J.N. Persson, O. Albohr, U. Tartaglino, A.I. Volokitin, E. Tosatti, On the nature of surface roughness with application to contact mechanics, sealing, rubber friction and adhesion, J. Phys. Condens. Matter 17 (2005) R1-R62.

[19] B.J.N. Persson, On the fractal dimension of rough surfaces, Tribol. Lett. 54 (2014) 99106.

[20] K.A. Alshibli, A.M. Druckrey, R.I. Ai-Raoush, T. Weiskittel, N.V. Lavrik, Quantifying Morphology of Sands Using 3D Imaging, J. Mater. Civil. Eng. 27(2014) 04014275.

[21] F.N. Altuhafi, M.R. Coop, V.N. Georgiannou, Effect of particle shape on the mechanical behavior of natural sands, J. Geotech. Geoenviron. Eng. 142(2016), 04016071.

[22] H. Yang, B.A. Baudet, T. Yao, Characterization of the surface roughness of sand particles using an advanced fractal approach, Proc. Royal Soc. A. 472 (2016) 20160524.

[23] T. Yao, B.A. Baudet, S.D.N. Lourenço, Quantification of the surface roughness of quartz sand using optical interferometry, Meccanica (2018) 1-8.

[24] B. Zhou, J. Wang, H. Wang, Three-dimensional sphericity, roundness and fractal dimension of sand particles, Géotechnique 68 (2018): 18-30.

[25] G.H. Bagheri, C. Bonadonna, I. Manzella, P. Vonlanthen, On the characterization of size and shape of irregular particles, Powder. Technol. 270 (2015) 141-153. 
[26] F. Altuhafi, M. Coop, Changes to particle characteristics associated with the compression of sands, Géotechnique 61 (2011) 459-471

[27] J.K. Anochie-Boateng, J.J. Komba, G.M. Mvelase, Three-dimensional laser scanning technique to quantify aggregate and ballast shape properties, Constr. Build. Mater. 43 (2013) 389-398

[28] Y. Sun, B. Indraratna, S. Nimbalkar, Three-dimensional characterisation of particle size and shape for ballast, Géotech. Lett. 4 (2013) 197-202.

[29] Y. Guo, V. Markine, J. Song, G. Jing, Ballast degradation: Effect of particle size and shape using Los Angeles Abrasion test and image analysis, Constr. Build. Mater. 169 (2018) 414-424.

[30] J. Fonseca, C. O’Sullivan, M.R. Coop, P.D. Lee, Non-invasive characterization of particle morphology of natural sands, Soils. Found. 52 (2012) 712-722.

[31] P. Cignoni, M. Callieri, M. Corsini, M. Dellepiane, F. Ganovelli, G. Ranzuglia, MeshLab: an Open-Source Mesh Processing Tool, in Proceedings of Sixth Eurographics Italian Chapter Conference, 2008, pp. 129-136.

[32] F. Bernardini, J. Mittleman, H. Rushmeier, C. Silva, G. Taubin, The ball-pivoting algorithm for surface reconstruction, in IEEE Transactions on Visualization and Computer Graphics 5, 1999, pp. 349-359.

[33] R. Ehrlich, B. Weinberg, An exact method for characterization of grain shape, J. Sediment. Petrol. 40 (1970) 205-212.

[34] P.R. Nayak, Random process model of rough surfaces, J. Lubr. Technol. 93 (1971) 398407

[35] Z. Nie, X. Wang, Z. Liang, J. Gong, Quantitative analysis of the three-dimensional roundness of granular particles, Powder Technol. 336 (2018) 584-593.

[36] H. Wadell, Volume, shape, and roundness of rock particles, J. Geol 40 (1932) 443-451.

[37] J. Zheng, R.D. Hryciw, Traditional soil particle sphericity, roundness and surface roughness by computational geometry, Géotechnique, 65 (2015) 494 - 506. 
[38] B.D. Zhao, J.F. Wang, 3D quantitative shape analysis on form, roundness, and compactness with $\mu \mathrm{CT}$, Powder Technol. 291 (2016) 262-275.

[39] T. Xu, I.D. Moore, J.C. Gallant, Fractals, fractal dimensions and landscapes - a review. Geomorphology 8 (2013) 245-262.

[40] W.L. Power, T.E. Tullis, Euclidean and fractal models for the description of rock surface roughness, J. Geophys. Res.: Sol Ea. 96 (1991) 415-424.

[41] P.E. Helland, P.H. Huang, R.F. Diffendal, SEM analysis of quartz sand grain surface textures indicates alluvial/colluvial origin of the Quaternary "glacial” boulder clays at Huangshan (Yellow Mountain), East-Central China, Quat. Res. 48 (1997) 177-186.

[42] A.K. Warrier, H. Pednekar, B.S. Mahesh, R. Mohan, S. Gazi, Sediment grain size and surface textural observations of quartz grains in late quaternary lacustrine sediments from Schirmacher Oasis, East Antarctica: Paleoenvironmental significance, Polar Sci. 10 (2016) 89-100.

[43] A. Ersoy, M.D. Waller, Textural characterisation of rocks, Eng. Geol. 39 (1995) 123-136.

[44] D. Sarocchi, R. Sulpizio, J.L. Macías, R. Saucedo, The 17 July 1999 block-and-ash flow (BAF) at Colima Volcano: New insights on volcanic granular flows from textural analysis, J. Volcanol. Geotherm. Res. 204 (2011) 40-56. 


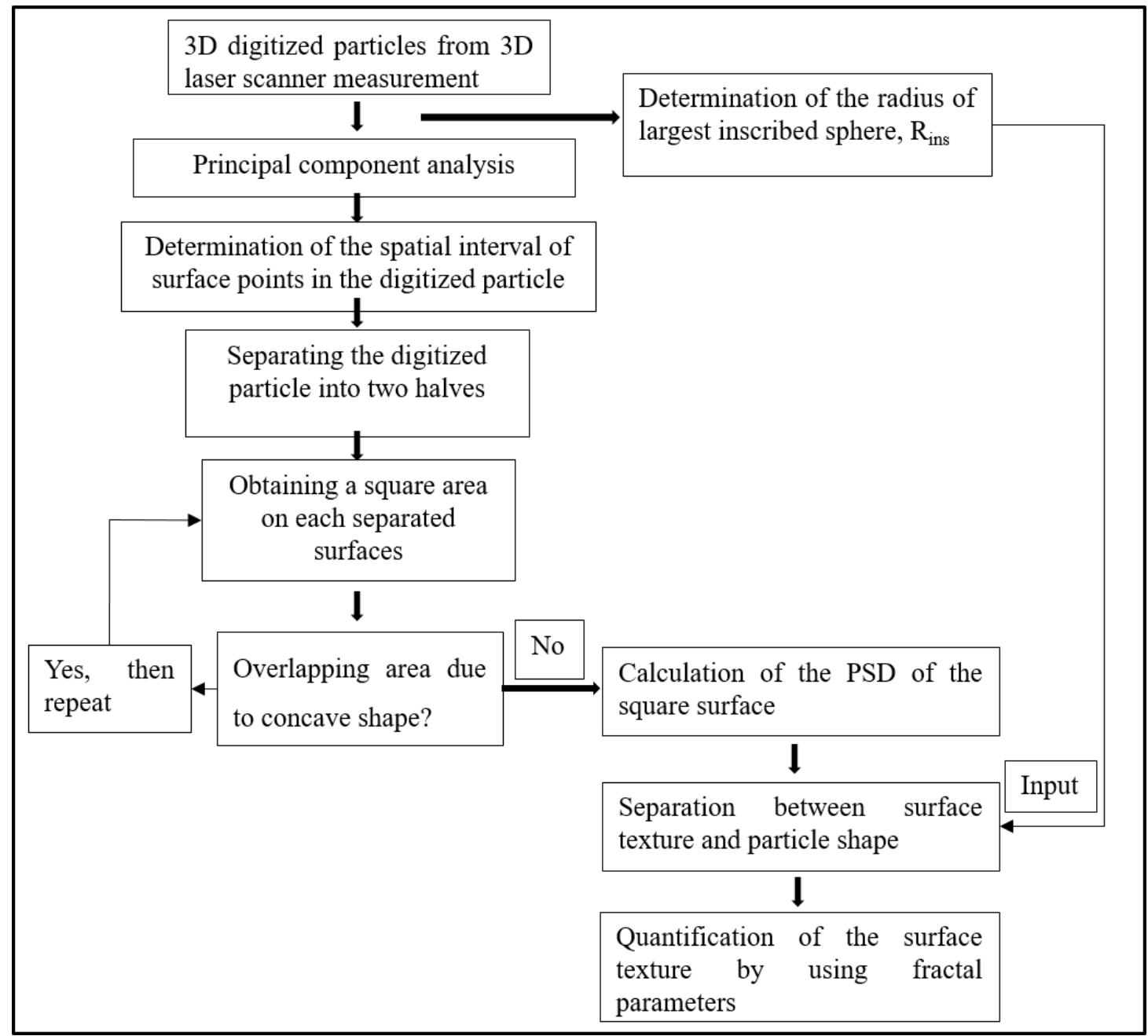

Figure 1. Flow chart for defining the surface texture from the 3D laser scanner measurement for gravel and its quantification using fractal method. 

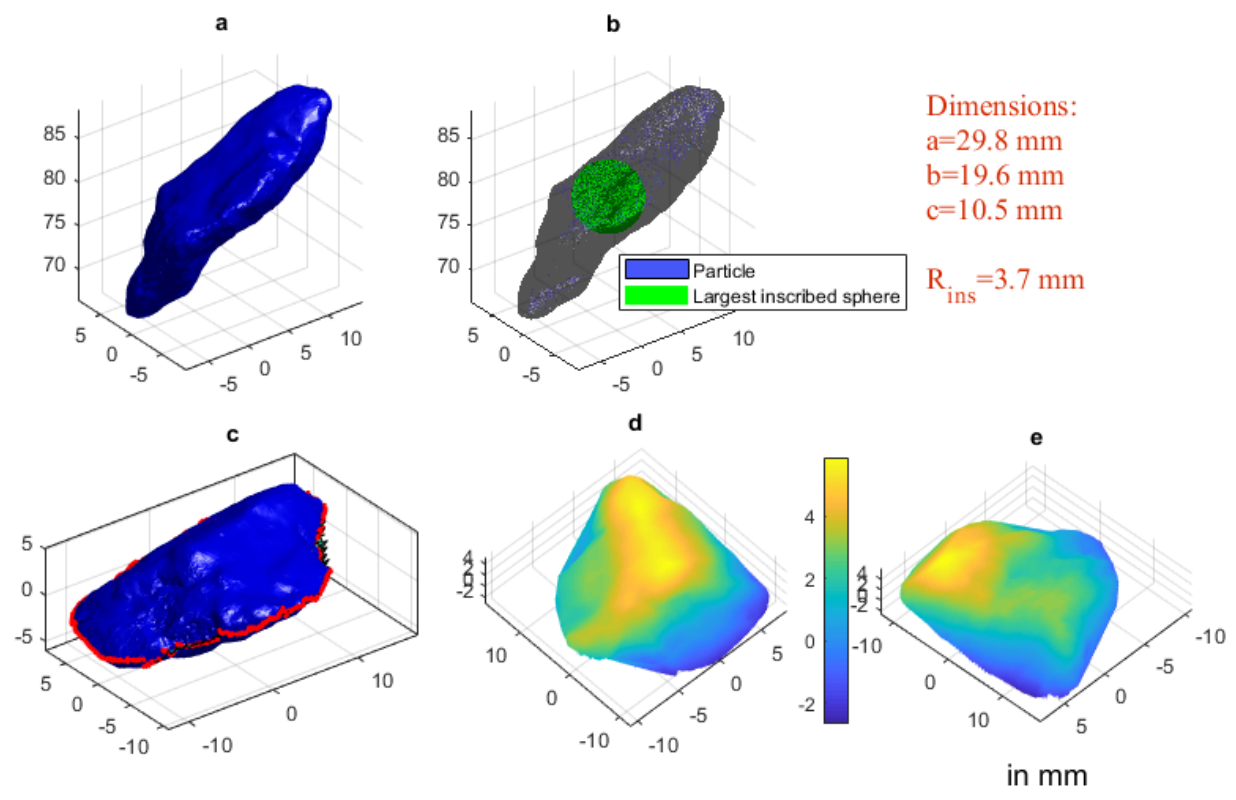

Figure 2. Procedure to separate the particle. a. Scanned particle; $b$, determination of the largest inscribed sphere, c. particle after the principal component analysis; $d$ upper half surface; e. lower half surface. ( $\mathrm{a}, \mathrm{b}$ and $\mathrm{c}$ in legend represents the dimensions of the particle and $R_{\text {ins }}$ is the radius of the largest inscribed sphere)
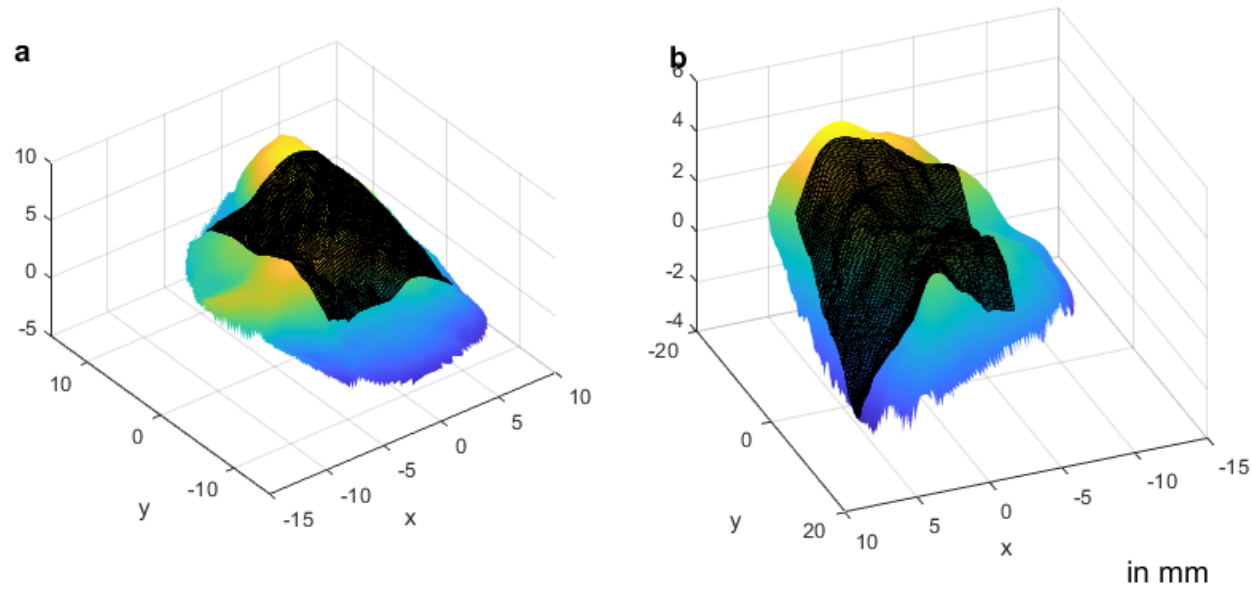

Figure 3. Retrieved area (indicated by black color) from two surfaces. The side length of the projected square area is $18.6 \mathrm{~mm}$. 

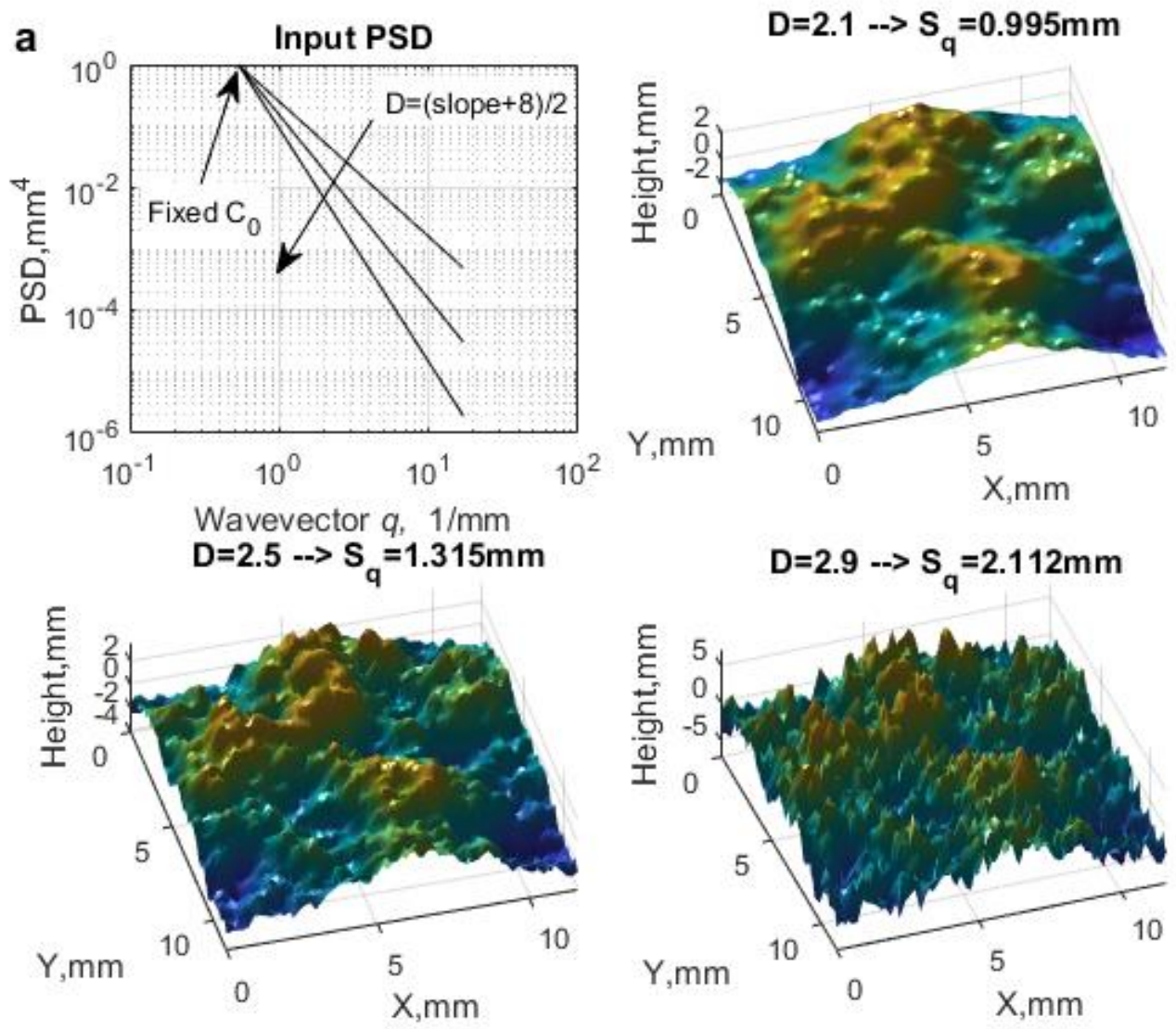

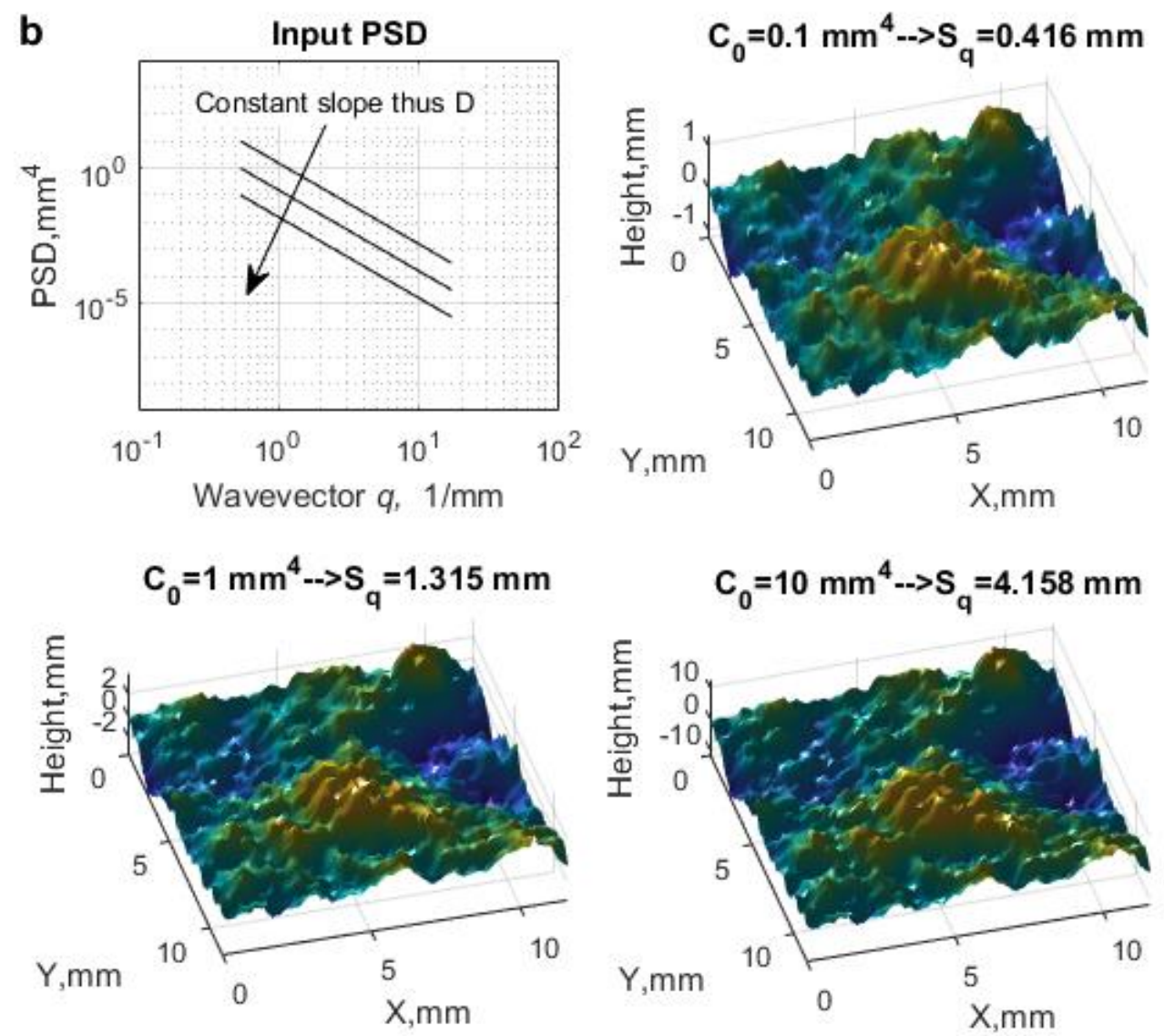

Figure 4. Illustration of the parameters (a) $D_{\mathrm{PSD}}$ and (b) $C_{0}$ on the input PSD and the reconstructed surfaces using the method proposed by Persson et al. [18]. 

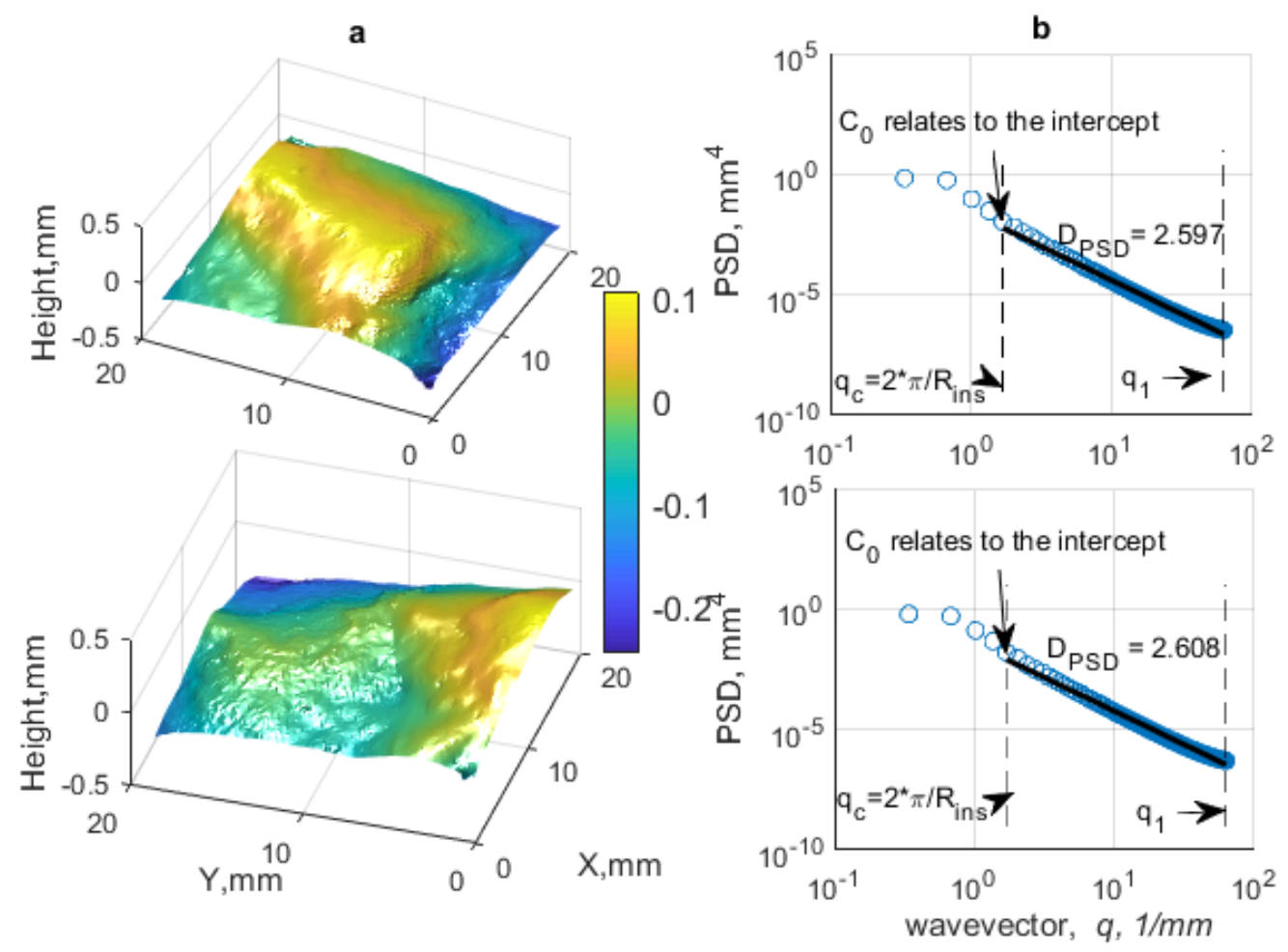

For projected square area of $18.6 * 18.6 \mathrm{~mm}^{2}, \mathrm{R}_{\text {ins }}=3.7 \mathrm{~mm}$

Figure 5. Example of fractal scaling at a large scale (using 3D laser scanning) for (a) a square area with side length of $18.6 \mathrm{~mm}$ using the (b) Power Spectrum Density (PSD) method with a threshold wavevector defined by $2 \pi / R_{\text {ins }}$ (equals to $3.7 \mathrm{~mm}$ ). 

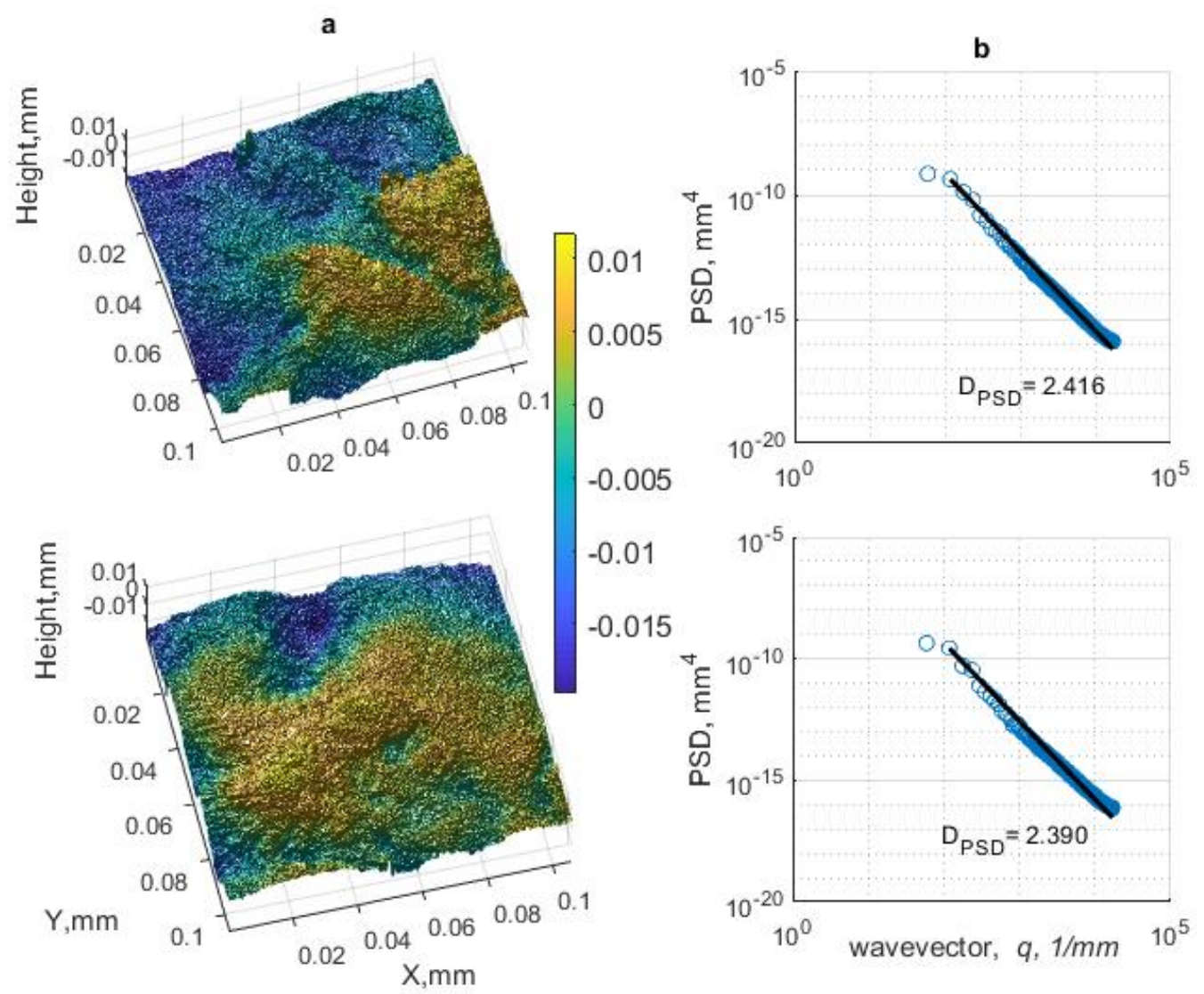

Figure 6. Example of fractal scaling at a small scale (using interferometry) for (a) a square measuring area with side length of $0.106 \mathrm{~mm}$ using the (b) Power Spectrum Density method 


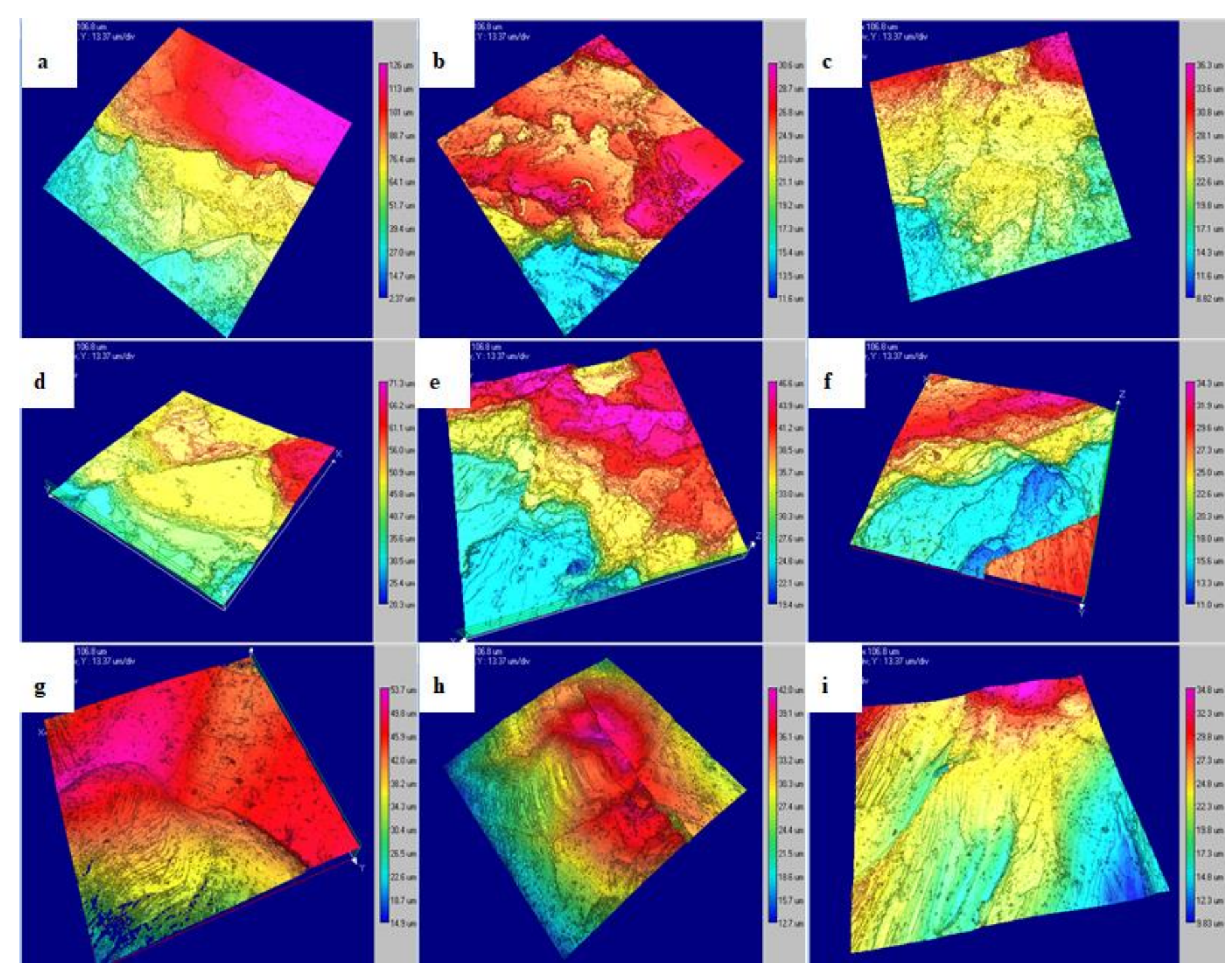


Figure 7. Surface texture of different minerals at a small scale, a-c: biotite; d-f: feldspar; g-i: quartz 


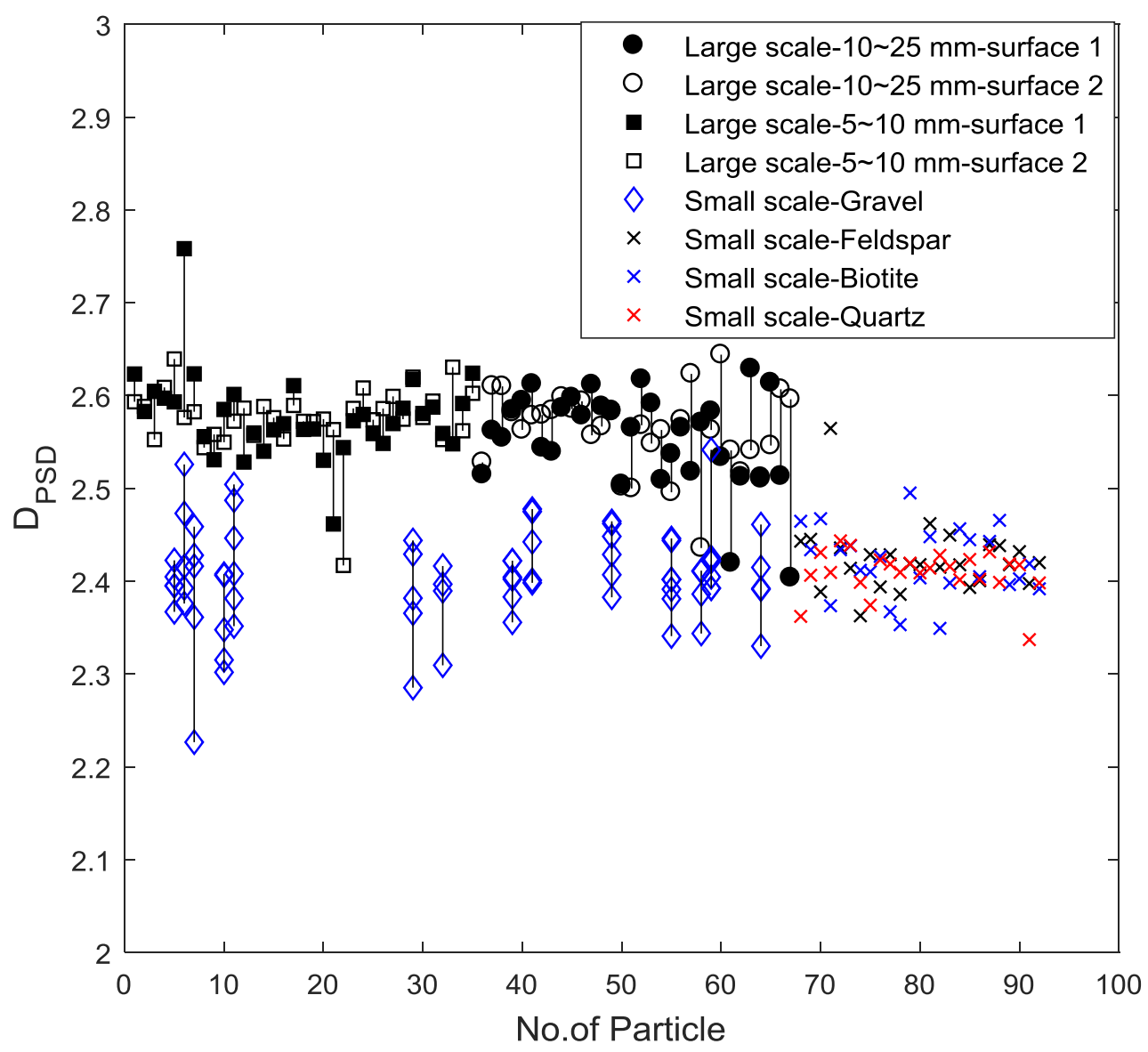

Figure 8. Fractal dimensions from the Power Spectral Density method (PSD) at large and small scales for gravel and sand particles. 


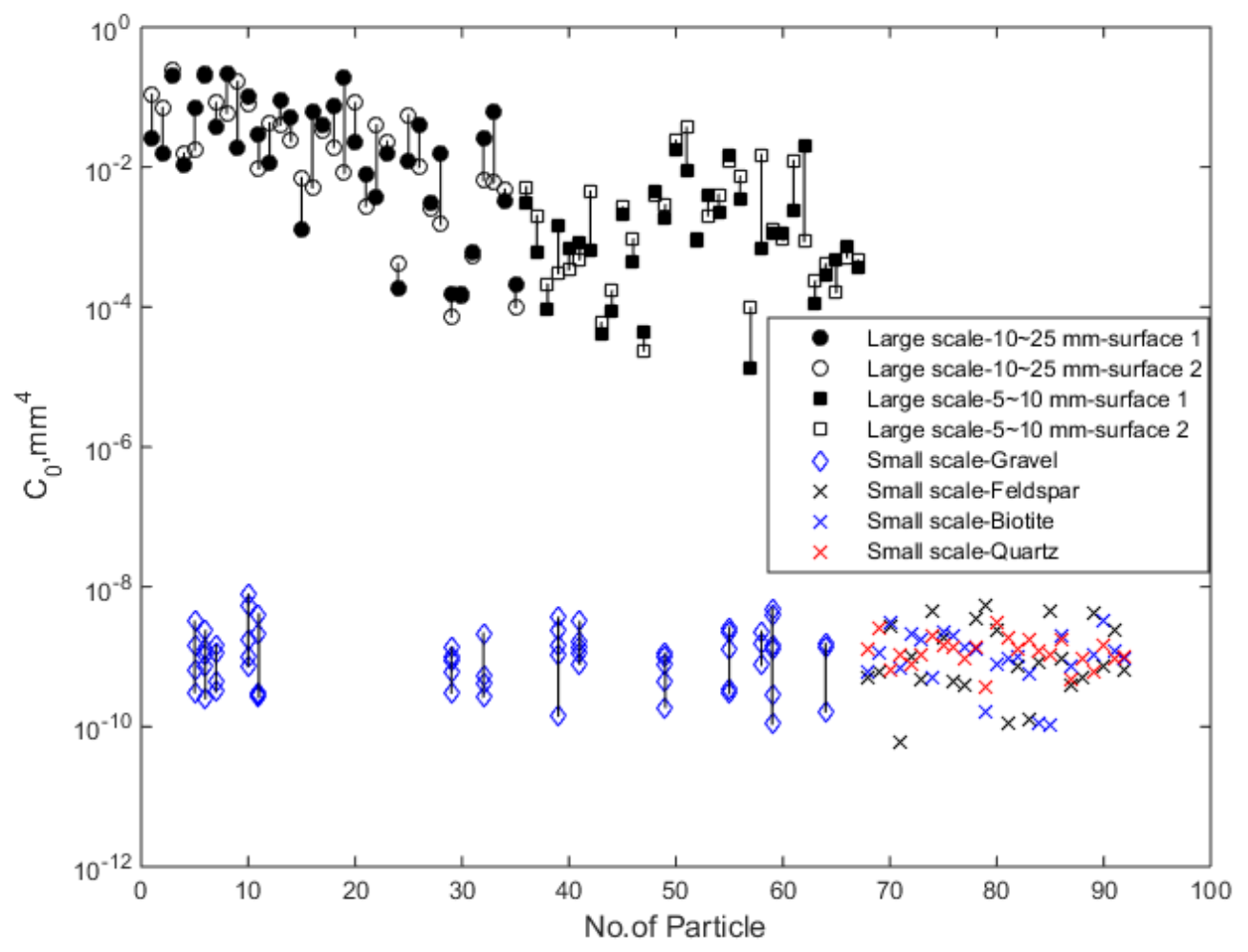

Figure 9. $C_{0}$ from the Power Spectral Density method (PSD) at large and small scales for gravel and sand particles. 


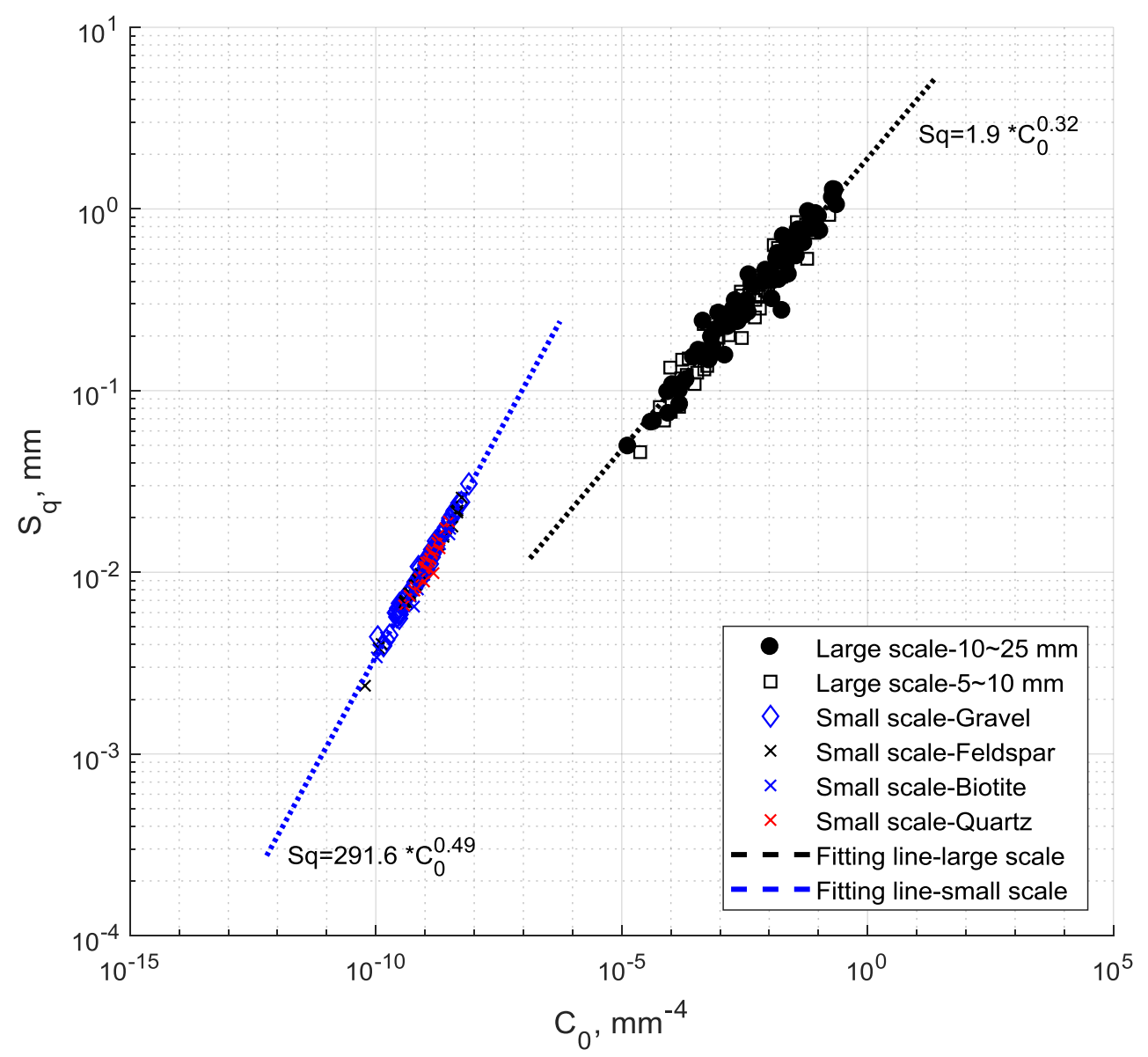

Figure 10. $S_{\mathrm{q}}$ determined from the PSD (from Eq (3)) against values of $C_{0}$ (from $\mathrm{Eq}(2))$ with the best fit lines. 


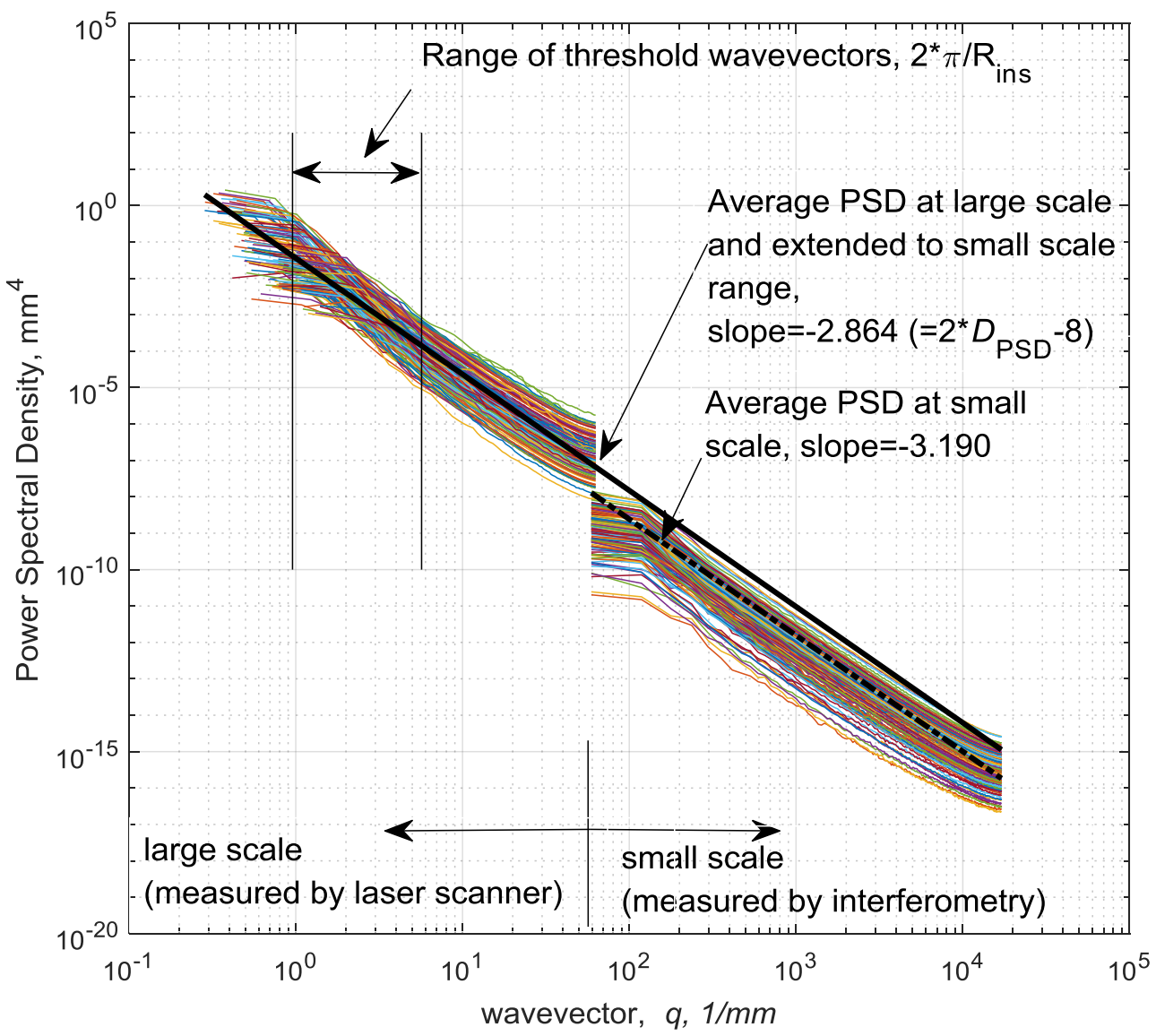

Figure 11. PSDs (colored lines) for surfaces at large (left) and small scales (right) with the vertical black lines indicating the range of threshold wavevector at large scale. The bold black line indicates the average PSD at a large scale which was extended to a small scale range. The dashed bold black line indicates the average PSD at a small scale. 


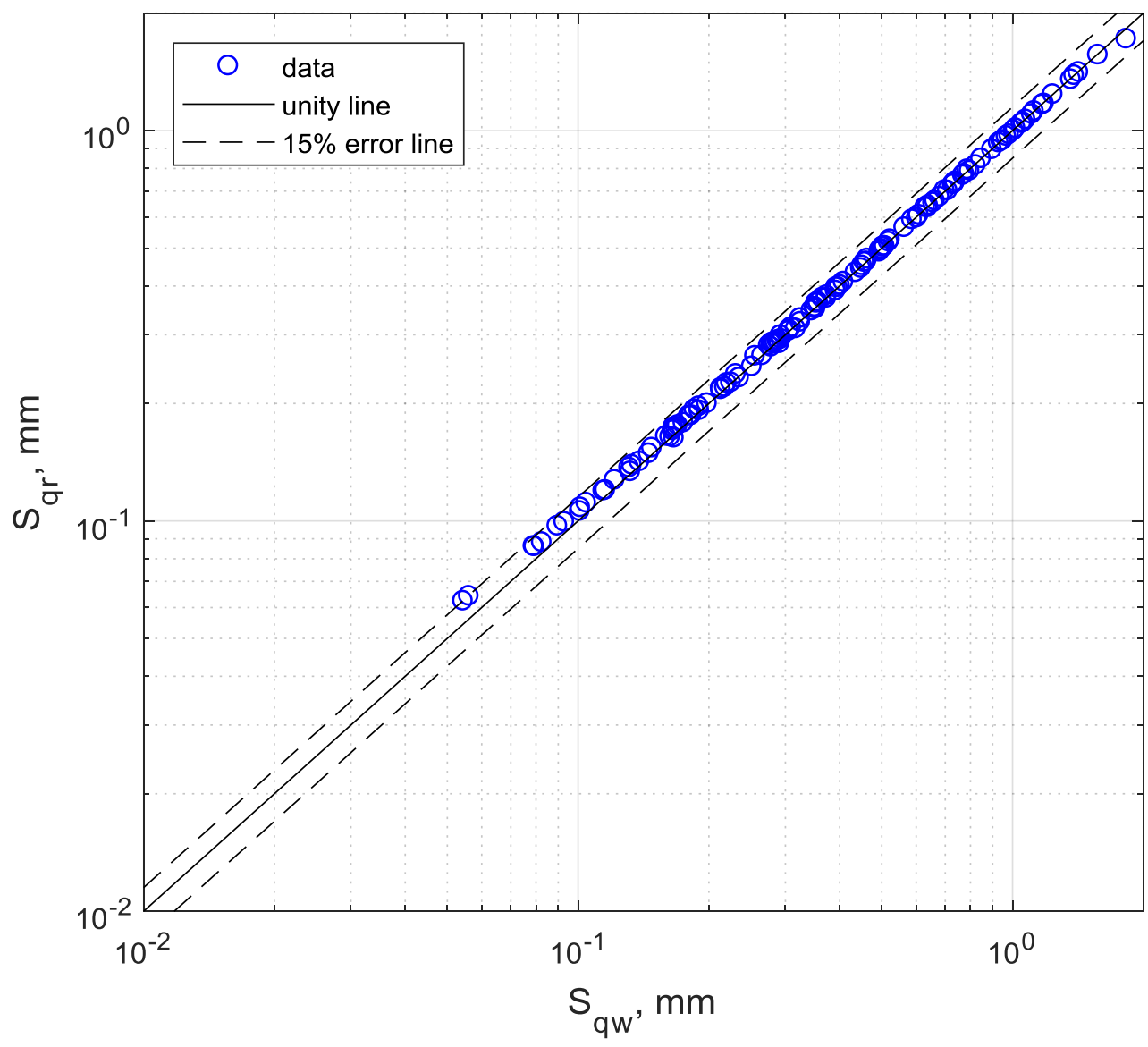

Figure 12. Comparison of $S_{\mathrm{q}}$ values; $S_{\mathrm{q} \_ \text {w }}$ by assuming a single fractal dimension for both scales and $S_{\mathrm{q} \_\mathrm{r}}$ by using different fractal dimension at the same scale. 